\title{
Profesyonel Sürücülükte Sürücü Davranışlarına Yönelik Nitel Bir Çalışma Şerife Yılmaz ${ }^{*}$ (D), Bahar Öz ${ }^{1}$ (D), Türker Özkan¹
}

${ }^{1}$ Güvenlik Araştırma Birimi, Psikoloji Bölümü, Orta Doğu Teknik Üniversitesi, Ankara Türkiye.

$\ddot{O} z$

Sürücü hatası kazaların meydana gelmesinde önemli bir paya sahiptir. Profesyonel sürücüler de trafikte uzun saatler geçirdiğinden kazalara karışma olasılığı yüksek olan bir gruptur. Fakat literatürde profesyonel sürücülerin sürücü davranışlarını tespit etmeye ve anlamaya yönelik yapılmış nitel çalışma sayısı çok azdır. Bu çalışma kapsamında profesyonel sürücülerin trafikte sergiledikleri sürücü davranışları derinlemesine incelenmiştir. Bu amaçla, farklı profesyonel sürücü gruplarından 26 sürücü ile yarı yapılandırılmış görüşmeler yapılmış ve görüşmeler içerik analizine tabi tutulmuştur. Elde edilen davranış örnekleri hata, sıradan ihlal, agresif ihlal ve pozitif sürücü davranışları olarak dört gruba ayrıştırılmıştır. Yapılan çalışma sonucunda profesyonel sürücülüğün profesyonel olmayan sürücülükten ayrışan davranış örnekleri sergiledikleri ve bu durumun sürücülerin kullandıkları araç tipine bağlı olarak da değişiklik gösterdiği bulunmuştur. Çalışmanın içerik analizi sonuçları ayrıntılı bir şekilde sunulmuş ve tartışılmıştır.

Anahtar Kelimeler: profesyonel sürücü, profesyonel sürücülük, sürücü davranışı, içerik analizi

\section{A Qualitative Study of Driving Behaviors of Professional Driving}

\begin{abstract}
Human error is a dominant factor in the occurrence of road traffic accidents. Professional drivers on the other hand are more likely to involve in road traffic accidents due to their long driving hours in traffic. However, par so many studies conducted on driving behaviors of professional drivers. Therefore, in the current study, it was aimed to investigate thoroughly the driving behaviors of professional drivers. For this reason, semi-structured interviews were conducted with 26 professional drivers. The interviews were content analyzed and the obtained behavioral examples were classified as error, ordinary and aggressive violation, and positive driver behavior. As a result of the study, it was found that professional driving differs from nonprofessional driving with some distinctive behavioral examples. Moreover, further distinction could be observed as a function of vehicle type. The results of the study were presented in detail and discussed.
\end{abstract}

Keywords: professional driver, professional driving, driver behavior, content analysis

\footnotetext{
* Illetişim / Contact: Şerife Yılmaz, BZ8-A, Psikoloji Bölümü, Orta Doğu Teknik Üniversitesi, Ankara Türkiye. E-Posta / Email: seerifee.yilmaz@gmail.com

Gönderildiğ́i tarihi / Date submitted: 11.02.2019, Kabul edildiği tarih / Date accepted: 25.04.2019

Alıntı / Citation: Yılmaz, Ş., Öz, B. ve Özkan, T. (2019). Profesyonel sürücülükte sürücü davranışlarına yönelik nitel bir çalışma. Trafik ve Ulaşım Araştırmaları Dergisi, 2(1), 51-65.
} 


\section{Profesyonel Sürücülükte Sürücü Davranışlarına Yönelik Nitel Bir Çalışma}

Dünya Sağlık Örgütü’nün 2018 yılında yayımladığı rapora göre her yıl 1,3 milyon insan trafik kazaları sonucu hayatını kaybetmektedir. Bu kazaların çoğu ekonomik büyüme hızına paralel olarak düşük ve orta gelirli ülkelerde meydana gelmektedir. Özellikle düşük gelir seviyesine sahip ülkelerde, yüksek gelir seviyesine sahip ülkelere kıyasla trafik kazalarından kaynaklanan ölümler 3 kat daha fazla olarak rapor edilmiştir (WHO, 2018). Türkiye'deki kaza istatistiklerine göre 2016 yılında 7.300 kişi trafik kazaları sonucunda hayatını kaybetmiştir. Sürücü hatası \%89.6'lık payıyla bu kazaların meydana gelmesindeki öncü faktör olarak kendini göstermektedir (Türkiye İstatistik Kurumu [TÜİK], 2017). Kazalara karışan araç tipleri incelendiğinde iş amaçlı kullanılan araçların tüm araç tipleri içerisindeki yüzdesinin \%26.4 olduğu görülmektedir. Bu araçların \%15,7'si van tipi araçlar, \%3,1'i minibüsler, \%2,9'u kamyonlar, \%2,4'ü çekici kamyonlar ve \%2,3'ü otobüslerdir (TÜİK, 2017). Sürücü davranışları ve farklı sürücü gruplarının kazaya karışmaları arasındaki ilişki literatürdeki farklı çalışmalarca ortaya konmuştur. Örneğin; kamyon sürücüleri için ihlallerle kazaya karışma arasında (af Wåhlberg, Dorn ve Kline, 2011; Sullman, Meadows ve Pajo, 2002), otobüs sürücüleri içinse hatalarla kazaya karışma arasında pozitif yönlü bir ilişki bulunmuştur (af Wåhlberg ve ark., 2011). Bir çalışmada iş amaçlı araç kullanan sürücülerin yaş, cinsiyet ve sürdükleri kilometre bakımından kendileriyle benzer olan sürücülere kıyasla \%29-\%50 daha fazla yaralanmalı kazalara karıştığı bulunmuştur (Baughan, Pearce, Smith ve Buckle, 2003). Öte yandan iş amacıyla araç kullanan sürücülerin şahsi araç kullanıcılarına göre daha fazla hız yapma davranışı raporladığı Newnam, Watson ve Murray (2004) tarafından gösterilmiştir.

İşinin bir parçası olarak sürücülük yapan kişiler profesyonel sürücü olarak tanımlanmaktadır. Mesleği gereği sürücülük yapan bu grubu tanımlamak için çalışmalarda kurumsal sürücüler (Newnam ve ark., 2004) ve işle ilgili olarak araç kullanan sürücüler (Wills, Watson ve Biggs, 2006) gibi terimler kullanılmıştır. Şimdiki çalışma kapsamında bu grup "profesyonel sürücüler" olarak adlandırılacaktır. Profesyonel sürücüler uzun mesafeler araç kullanmaları sebebiyle trafik kazalarına karışma olasılığı yüksek bir grup olarak görülmektedir (Baker, Wong ve Baron, 1976). Buna rağmen literatürde profesyonel sürücülükle ilgili az sayıda çalışma bulunmaktadır. Özellikle de yukarıda verilen istatistiklerin işaret ettiği gibi insan hatası trafik kazalarının oluşmasında önemli bir paya sahipken profesyonel sürücülerin trafik kazalarına karışmalarına neden olabilecek sürücü davranışları üzerine yapılmış nitel çalışmalar literatürde oldukça azdır (örneğin; Tanvir, Habib ve Walker, 2018). Literatürdeki bu boşluğu doldurmak için bu çalışmada profesyonel sürücülerin trafikte sergiledikleri sürücü davranışları örneklerine ulaşmak amacıyla farklı gruptan profesyonel sürücülerle görüşmeler yapılması hedeflenmiştir.

\subsection{Profesyonel ve Profesyonel Olmayan Sürücülük}

Profesyonel olan ve olmayan sürücülük arasında birtakım farklılıklar vardır. Örneğin; profesyonel olmayan sürücülükte (şahsi araç sürücüleri gibi) sürücünün hangi yolu kullanacağı, ne zaman, hangi araçla, hangi hızda araç kullanacağı kendi kararına bağlı olduğundan sürücü daha özerktir. Öte yandan profesyonel sürücülük; önceden belirlenmiş bir zaman tablosuna ve çalışma saatlerine bağlı olarak hareket etmeyi gerektirdiğinden sürücüye daha az özerklik sunar (Caird ve Kline, 2004). Buradan hareketle profesyonel sürücülük bazı önceden belirlenmiş yükümlülükler içerirken profesyonel olmayan sürücülükte sürüşün riskleri ve zorluğu büyük oranda sürücünün kontrolündedir denebilir (Caird ve Kline, 2004). Ek olarak profesyonel sürücülerin işleri gereği bazen aşina olmadıkları çevrelerde uzun mesafeler kat etmeleri gerekebilir (Lam, 2004). Ayrıca profesyonel sürücülerin ne düzeyde güvenli sürüş sergileyecekleri bağlı oldukları kurum kültürü, iklimi, kurumun güvenlik prosedürleri ve uygulamaları gibi çeşitli dış faktörlere de bağlıdır (Öz, Özkan ve Lajunen, 2013). Örneğin; Öz ve ark. 2013 yılında yaptıkları çalışmada; kurumların iş ve zaman baskısı konusundaki

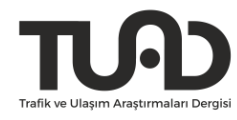


hassasiyetleri arttıkça sürücülerin daha az hata ve ihlal raporladıkları, güvenlik konusuna ve ilgili uygulamalara önem verildikçe de sürücülerin güvenlik becerilerinin güçlendiği bulgularına ulaşmıştır. Dahası profesyonel sürücüler bu uygulama ve kurum işleyişi üzerinde ilk söz söyleme hakkına sahip değillerdir (Caird ve Kline, 2004). Sonuç olarak profesyonel sürücüler, kurum kural ve düzenlemelerine uyarken aynı zamanda yol durumu ve beraberinde gelen değişkenleri de (örn; aydınlatma, mevsim ve yol koşulları) göz önünde bulundurarak sürüş gerçekleştirirler (Caird ve Kline, 2004).

\subsection{Bir İnsan Faktörü Unsuru Olarak Sürücülükte Sürücü Davranışları}

Sürücülükte insan faktörü; sürücü davranışları (stili) ve sürücü becerileri (performansı) olarak iki ana başlık altında ele alınmaktadır. Sürücü davranışı bir sürücünün sürüş sırasında sergilediği tipik davranış olarak tanımlanır (Oppenheim ve Shinar, 2011). Örneğin; sürücünün aracı nasıl kullanmayı tercih ettiği, ya da hız tercihi, sollama yapması, ihlal yapıp yapmaması gibi sürüş alışkanlıkları anlamına gelebilir (Elander, West ve French, 1993). Sürücü becerileri ise sürücünün bir durum karşısında güvenlikle ilgili becerileri veya algısal motor kapasitesi ile ilgilidir (Oppenheim ve Shinar, 2011). Bir sürücünün ortaya koyabileceği en iyi performans olarak nitelendirilebilir. Bu çalışma kapsamında sürücü davranışlarına odaklanılacaktır.

Reason (1990) insan hatasını, davranışı sergilemek için gerekli olan niyete göre farklı tiplere ayrıştırmıştır. Reason'un insan hatası sınıflandırmasında davranışları niyet temelinde ayrıştırmak için üç temel soru sorulmaktadır. Şekil 1'de de görüldügüü üzere sorulara verilen cevaplar doğrultusunda davranışlar; istemsiz/niyetsiz davranış (non-intentional), kasıtsız davranışlar (unintentional behavior; slips ve lapses) ve hatalı veya başarılı davranış olarak ayrılır. $\mathrm{Bu}$ çalışma kapsamında aksiyon öncesinde bir niyeti/amacı olan kırmızı daire ile belirtilmiş kısma odaklanılacaktır.

Reason, Manstead, Straddling, Baxter ve Campbell, 1990 yılında bu sürücü davranışları sınıflandırması temelinde öz beyana dayanan bir Sürücü Davranışları Anketi'ni (SDA) geliştirmişlerdir. $\mathrm{Bu}$ ankette sürücü davranışları hatalar ve ihlaller olarak iki temel gruba ayrılmıştır. 520 katılımcıyla yürütülen çalışma sonucunda davranışlar 3 boyuta ayrışmıştır; kasıtlı ihlaller, tehlikeli hatalar ve dikkatsizlik sonucu oluşan hatalar (dalgınlık ve dikkatsizlik). Hatalar; planlanan aksiyonun istenen sonuca ulaşamaması olarak tanımlanırken ihlaller güvenli uygulamalardan kasıtlı olarak sapma davranışı sergilemek olarak tanımlanmıştır (Reason ve ark., 1990). Hatalar daha sonra dalgınlık ve dikkatsizlikler ve yanlışlar (mistakes) olarak ikiye ayrılmıştır. Dikkatsizlikler (slips) gözlenebilir hatalar olarak tanımlanmış, dalgınlıklar (lapses) ise örtülü hafiza hataları olarak nitelendirilmiştir (Reason ve ark., 1990). Reason (1990) planlanan aksiyonun hatalı uygulanmasını ihmal ve dalgınlık olarak nitelerken (uygulama ve depolama hataları) önceki niyetle planlanan sonuç arasındaki tutarsızlığı yanlışlar (planlama hataları) olarak tanımlamıştır. Dalgınlıklar ve ihmaller Rasmussen'in beceri, kural, bilgi sınıflamasındaki beceri odaklı davranışlara denk düşmektedir. Dahası Rasmussen'in sınıflandırmasına dayanarak (1983), Reason ve ark. (1990) yanlışları bilgi odaklı ve kural odaklı yanlışlar olarak iki sınıfa daha ayırmıştır. Bilgi odaklı yanlışlar daha sonraları hatalar olarak adlandırılırken kural odaklı yanlışlar literatürde ihlaller olarak bilinmektedir.

1997 yılında Lawton, Parker, Manstead ve Stradling SDA'ya yeni ihlal maddeleri ekleyerek 830 kişinin katılımıyla bir çalışma yapmış ve çalışma sonunda ihlalleri sıradan ihlaller ve saldırgan ihlaller olarak ikiye ayırmıştır. Sıradan ihlaller saldırgan bir motivasyon olmaksızın güvenli sürüş uygulamalarından kasıtlı olarak sapmak anlamına gelirken agresif ihlaller gözlenebilir agresif davranışlar içermektedir.

\section{TQD}




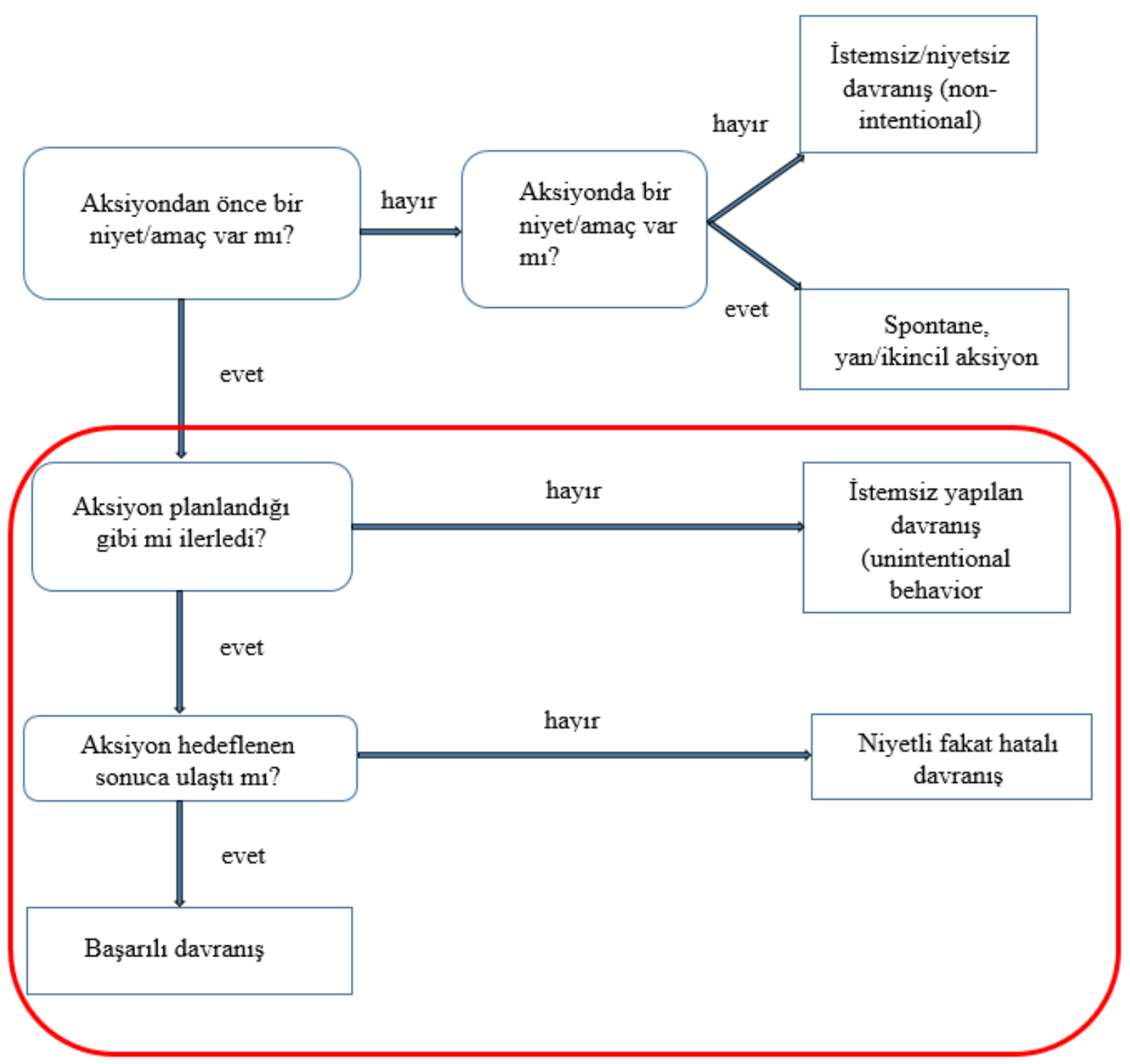

Şekil 1. Reason'un insan hatası sınıflandırması (1990)

Özkan ve Lajunen (2005), trafik ortamında sapkın olmayan bazı davranışların da sergilendiğini söyleyerek diğer yol kullanıcıları ve trafiğin gözetilmesine yönelik yapılan bu davranışları pozitif sürücü davranışları olarak tanımlamıştır. Geliştirdikleri yeni davranış ölçümüyle literatüre katkı sağlayan araştırmacılar, Türkiye'den 312 sürücü ile gerçekleştirdikleri çalışmada hata ve ihlallere ek olarak pozitif sürücü davranışlarını yeni bir boyut olarak ortaya koymuşlardır.

Literatürde sürücü davranışlarının farklı boyutlarını ölçen çeşitli ölçekler bulunmaktadır. Örneğin; Sürücü Davranışları Anketi (Reason ve ark., 1990), Dula Tehlikeli Sürüş Endeksi (Dula ve Ballard, 2003), Çokboyutlu Sürüş Stili Envanteri (Taubman-Ben-Ari, Mikulincer ve Gillath, 2004), Kurumsal Sürücü Davranışları Ölçeği (Newnam, Greenslade, Newton ve Watson, 2011), Prososyal ve Agresif Sürüş Envanteri (Harris ve ark., 2014) bu ölçeklerden bazılarıdır. Bunların içinde en popüler olan SDA, profesyonel ve profesyonel olmayan sürücülerin sürücü davranışlarını ölçmek için araştırmacılar tarafından yaygın olarak kullanılmaktadır. Profesyonel sürücü çalışmalarında bu anket kendi orijinal yapısı ile kullanıldığı gibi (örn; Öz, Özkan ve Lajunen, 2014; Öz ve ark., 2013; Sullman ve ark., 2002), anket üzerinde yapılan bazı düzenlemeler sonucu farklı versiyonlarda da kullanılmaktadır (örn; Wang, Li, Feng ve Peng, 2014). Dilinde yapılan bazı düzenlemeler veya ölçeğe eklenen 
maddeler sonrası SDA, profesyonel sürücü grubuyla yapılan çalışmalarda farklı sayıda ve içerikte faktör yapıları ortaya koymuştur. Örneğin; hata ve ihlal boyutlarının yanı sıra (örn; Wills ve ark., 2006; Freeman, Davey ve Wishart, 2008), dikkat dağıtan sürüş (Wills ve ark., 2006), yolculuk öncesi araç bakımı (Wills ve ark., 2006), yorgunluk (Freeman ve ark., 2008), tehlikeli sürüş, hız, normal sürüş limitlerinin aşımı ve araç kontrol uygulamaları (Newnam, Watson ve Murray, 2002) gibi faktörler profesyonel sürücü grubunda SDA'nın ortaya koyduğu faktörlerden bazılarıdır. Faktör yapılarındaki çeşitlilik profesyonel sürücülerin profesyonel olmayan sürücülere göre farklı davranış örnekleri sergilediklerine işaret etmektedir. Bu farklı faktör yapılarının ortaya çıkma sebebi SDA'nın profesyonel sürücü grubu özelinde geliştirilmiş bir ölçüm aracı olmaması, dolayısıyla da profesyonel sürücülüğün profesyonel olmayan sürücülükten ayrışan davranış örneklerini içermemesinden kaynaklanan farklılıklar temelli olabilir.

Yukarıda bahsedilen çalışmalar 1şığında profesyonel sürücülüğün profesyonel olmayan sürücülükle benzer ve onlardan ayrışan davranış örnekleri sergiledikleri, bunların da farklı faktör yapılanmaları ile kullanılan ölçeklerde kendini gösterdiği sonucuna ulaşılmaktadır. Buradan hareketle, profesyonel sürücülerin trafikte sergiledikleri güvenlikle ilgili olabilecek davranışlarını derinlemesine anlamaya yönelik bir çalışma yapılması ihtiyacı olduğu görülmektedir. Literatürdeki bu boşluğu gidermek amacıyla bu çalışma kapsamında farklı profesyonel sürücü grubuna mensup kişilerle sürücü davranışları üzerine görüşmeler yapılması ve bu davranışların altında yatan olası sebeplerin belirlenmesi amaçlanmıştır. Buna ek olarak var olan ölçüm araçlarının güncellenmesi ve yenilerinin geliştirilmesi, iyileştirme ve müdahale programları geliştirilmesi ve uygulanması gibi süreçlere temel oluşması da çalışmanın trafik güvenliğine yönelik sunacağı katkılar arasında bahsedilebilir.

\section{Yöntem}

\subsection{Katılımcilar}

26 profesyonel erkek sürücünün katılımıyla yarı yapılandırılmış görüşmeler gerçekleştirilmiştir. Görüşme örneklemi; taksi $(N=5)$, dolmuş $(N=4)$, kamyon $(N=4)$, şehirlerarası otobüs $(N=3)$, ring servisi $(N=3)$, okul servisi $(N=2)$, şirket aracı $(N=2)$, semt servisi $(N=1)$, özel havaalanı otobüsü $(N=1)$, ve van tipi araç $(N=1)$ olmak üzere farklı tip araç kullanan sürücülerden oluşmaktadır. Sürücülerin yaşı 25 ile 60 arasında değişmekte olup ortalaması 38.07 olarak saptanmış $(S S=8,83)$, ve ortalama $21.33(S S=8,14)$ yıldır sürücü belgesi sahibi oldukları belirlenmiştir. Tablo 1'de görüşme katılımcılarının özellikleri özetlenmiştir.

Tablo 1. Görüşme katılımcılarının özellikleri

\begin{tabular}{|c|c|c|c|c|c|c|}
\hline & Yaş & Cinsiyet & Meslek & $\begin{array}{l}\text { Sürücü belgesine sahip } \\
\text { olunan süre (yıl) }\end{array}$ & $\begin{array}{l}\text { Aracı } \\
\text { kullandıkları } \\
\text { süre (yıl) }\end{array}$ & $\begin{array}{l}\text { Görüssme } \\
\text { yürütme } \\
\text { yöntemi }\end{array}$ \\
\hline 1 & 37 & Erkek & Taksi sürücüsü & 18 & 18 & Yüz yüze \\
\hline 2 & 44 & Erkek & Taksi sürücüsü & 26 & 26 & Yüz yüze \\
\hline 3 & 55 & Erkek & Taksi sürücüsü & 35 & 3 & Yüz yüze \\
\hline 4 & 45 & Erkek & Taksi sürücüsü & 22 & 22 & Yüz yüze \\
\hline 5 & 46 & Erkek & Taksi sürücüsü & 20 & 20 & Yüz yüze \\
\hline 6 & 44 & Erkek & Dolmuş sürücüsü & 27 & 27 & Yüz yüze \\
\hline 7 & 30 & Erkek & Dolmuş sürücüsü & 12 & 10 & Yüz yüze \\
\hline 8 & 41 & Erkek & Dolmuş sürücüsü & 19 & 16 & Yüz yüze \\
\hline 9 & 58 & Erkek & Dolmuş sürücüsü & 32 & 25 & Yüz yüze \\
\hline
\end{tabular}


Tablo 1. Devam

\begin{tabular}{|c|c|c|c|c|c|c|}
\hline 10 & 32 & Erkek & $\begin{array}{l}\text { Kamyon sürücüsü } \\
\text { (taşımacıllk) }\end{array}$ & 13 & 6 & Telefon \\
\hline 11 & 43 & Erkek & $\begin{array}{l}\text { Kamyon sürücüsü } \\
\text { (çekici) }\end{array}$ & 25 & 10 & Telefon \\
\hline 12 & 55 & Erkek & Kamyon sürücüsü & 32 & 15 & Skype \\
\hline 13 & 40 & Erkek & Kamyon sürücüsü & 18 & 17 & Telefon \\
\hline 14 & 60 & Erkek & $\begin{array}{l}\text { Şehirlerarası } \\
\text { otobüs sürücüsü }\end{array}$ & 39 & 31 & Yüz yüze \\
\hline 15 & 35 & Erkek & $\begin{array}{l}\text { Şehirleraras1 } \\
\text { otobüs sürücüsü }\end{array}$ & 17 & 16 & Yüz yüze \\
\hline 16 & 27 & Erkek & $\begin{array}{l}\text { Şehirleraras1 } \\
\text { otobüs sürücüsü }\end{array}$ & 8 & 2 & Yüz yüze \\
\hline 17 & 37 & Erkek & $\begin{array}{l}\text { Ring sürücüsü } \\
\text { (şehiriçi otobüs) }\end{array}$ & 9 & 6 & Yüz yüze \\
\hline 18 & 39 & Erkek & $\begin{array}{l}\text { Ring sürücüsü } \\
\text { (şehiriçi otobüs) }\end{array}$ & 21 & 8 & Yüz yüze \\
\hline 19 & 37 & Erkek & $\begin{array}{l}\text { Ring sürücüsü } \\
\text { (şehiriçi otobüs) }\end{array}$ & 18 & 8 & Yüz yüze \\
\hline 20 & 38 & Erkek & $\begin{array}{l}\text { Okul servisi } \\
\text { sürücüsü }\end{array}$ & 21 & 7 & Yüz yüze \\
\hline 21 & 36 & Erkek & $\begin{array}{l}\text { Okul servisi } \\
\text { sürücüsü }\end{array}$ & 19 & 15 & Yüz yüze \\
\hline 22 & 47 & Erkek & $\begin{array}{l}\text { Şirket arac1 } \\
\text { sürücüsü }\end{array}$ & 17 & 1.2 & Telefon \\
\hline 23 & 25 & Erkek & $\begin{array}{l}\text { Şirket arac1 } \\
\text { sürücüsü }\end{array}$ & 6 & 4 & Telefon \\
\hline 24 & 48 & Erkek & $\begin{array}{l}\text { Semt servisi } \\
\text { sürücüsü }\end{array}$ & 27 & 6 & Yüz yüze \\
\hline 25 & 43 & Erkek & $\begin{array}{l}\text { Özel havaalanı } \\
\text { otobüsü sürücüsü }\end{array}$ & 25 & 22 & Yüz yüze \\
\hline 26 & 50 & Erkek & $\begin{array}{l}\text { Van sürücüsü } \\
\text { (nakliyat) }\end{array}$ & 30 & 30 & Yüz yüze \\
\hline
\end{tabular}

\subsection{Görüşme Formunun Geliştirilmesi}

Reason'un insan hatası sınıflandırması 1şığında (Reason, 1990), profesyonel sürücülerin sürücü davranışlarını belirlemeye yönelik 6 sorudan oluşan yarı yapılandırılmış görüşme formu hazırlanmıştır. Görüşme formu temel olarak 2 bölümden oluşmaktadır; ilk bölümde demografik bilgiler almaya yönelik sorular (örn; yaş, eğitim seviyesi, kullanılan araç tipi, geçtiğimiz yıl içinde kat edilen yol, sürücü belgesine sahip olunan süre, meslekte geçirilen süre), ikinci bölümde davranış örneklerine ulaşmak amacıyla profesyonel sürücülerin trafik ortamında sergileyebilecekleri ihmal, hata, sıradan ve agresif ihlal, ve pozitif sürücü davranışları ile ilgili sorular sorulmuştur. Ek olarak sürücülere görüşme yürütücüsü tarafından iş amaçlı araç kullanmak ve şahsi amaçla araç kullanmak arasındaki farklar, profesyonel sürücülerin dahil olduğu kazaların nedenleri sorulmuştur. Katılımcıların soruları bir diğerinden ayırt edemedikleri veya anlamadıkları zamanlarda, görüşme yürütücüsü tarafından kendilerine bazı davranış örnekleri verilmiştir. Ayrıca, düşünmelerini kolaylaştırmak için neredeyse her sorunun ardından bazı kritik sorular kendilerine yöneltilmiştir; ilgili davranış tipiyle bağlantılı olarak deneyimledikleri veya şahit oldukları kritik olaylar, kendi sürücü gruplarını diğer profesyonel sürücü gruplarından ayıran davranış örnekleri ve bu davranışları trafik güvenliğiyle nasıl 
ilişkilendirdikleri gibi. Görüşme formunun geliştirildikten sonra trafik güvenliği alanında çalışmalar yapan bir yüksek lisans öğrencisiyle çevrimiçi ortamda paylaşılmış ve içerik, kapsam ve dil kullanımı ile ilgili geri bildirimleri istenmiştir. Gelen geri bildirimler sonrasında formun dilinde katılımcılardan tarafından anlaşılırlığını arttırmak için sadeleşmeye gidilmiş, form içerik olarak terimlerden arındırılmıştır. Bu düzenlemenin ardından form, durakta karşılaşılan iki profesyonel sürücü ile paylaşılmış ve yapılacak olan çalışmanın amacı kendilerine aktarıldıktan sonra kendilerinden soruların anlaşılırlığı ile ilgili olarak geribildirimleri istenmiştir. Profesyonel sürücülerden gelen dil kullanımı ve ifade tarzı ile ilgili geri bildirimler sonrasında form nihai haline kavuşmuş ve farklı profesyonel sürücü gruplarına uygulanmıştır.

\subsection{Görüșmelerin Yürütülmesi}

İlk olarak ODTÜ İnsan Araştırmaları Etik Kurulu'ndan görüşmelerin yürütülmesi için etik izin alınmıştır. Farklı profesyonel sürücü grupları (örn; taksi, dolmuş, otobüs) duraklarında ve sokaklarda yaklaşılarak görüşmeye davet edilmiştir. Ayrıca bazı katılımcılara kişisel bağlantılar aracılığıyla ulaşılmıştır. Görüşmeye katılmayı kabul eden sürücülerle görüşmeler; yüz yüze, telefon veya skype aracılığıyla gerçekleştirilmiştir. Yarı yapılandırılmış görüşmeler sırasında sorular makalenin ilk yazarı tarafindan çoğunlukla planlanan sıralama ile okunmuş, görüşmenin akışına göre bazen de soruların sıralaması yer değiştirmiştir. Katılımcıların izinleri alınarak görüşmeler sırasında ses kayıt cihazı kullanılmıştır. Bir görüşme hariç bütün görüşmeler birebir yürütülmüştür. Sadece bir görüşme sırasında iki katılımcı da aynı anda sorulara cevap vermiştir (bkz. Tablo 1).

\section{Bulgular}

\subsection{Görüşmelerin İçerik Analizi}

Her görüşme makalenin ilk yazarı tarafından kelimesi kelimesine deşifre edilmiş ve deşifre edilen görüşmelerden davranış örneklerine makale yazarlarının ortak değerlendirmeleri sonucu ulaşılmıştır. İlk olarak davranış örnekleri soru soru ayrıştırılmış ve cevabı veren sürücü grupları özelinde renklendirilmiştir. Ayrıca örneklerin raporlanma sıklığı verilen örneğin madde havuzunda olup olmayacağına karar vermek için hesaplanmıştır. Daha sonra bu davranış örnekleri içeriksel benzerliklerine göre gruplandırılmıştır. Bu işlem sonrasında davranış örnekleri; Reason'un insan hatası sinıflandırmasından (1990) faydalanılarak hata, sıradan ihlal, ve agresif ihlal, Özkan ve Lajunen'in (2005) pozitif sürücü davranışları ölçümünden faydalanılarak pozitif sürücü davranışları olmak üzere 4 grupta toplanmıştır. Görüşme katılımcıları bazı davranış örneklerini farklı tip davranış örneğine ulaşmayı hedefleyen sorulara da verdiklerinden, verilen cevaplar soru seviyesinde değil içeriksel benzerliklerinden yola çıkarak davranış tipine göre sınıflandırılmıştır. Katılımcıların beyanlarından bazı davranış örneklerinin trafikte karşılaşılan farklı durumlara göre türetilmiş olduğu görülmüştür. Örneğin; ana temasına göre "diğer yol kullanıcılarına yol vermek" olarak ele alınacak olan bir pozitif sürücü davranışı, "sollama sırasında diğer yol kullanıcılarına yol vermek", "geçiş hakkı bende olsa dahi kavşaktaki sıkışık tarafa yol vermek" gibi durumsal örneklerle birleşerek katılımcılar tarafindan türetilmiştir. Bu tip durumsal örneklerden öne çıkanlar aşağıdaki bölümde koyu yazılarak belirtilen ana temaya ek olarak raporlanmıştır. Sonuç olarak katılımcıların görüşme sorularına verdikleri cevaplara dayanarak trafik ortamında deneyimledikleri sıradan ve agresif ihlallere yönelik davranış örnekleri "ihlal” başlığı altında, dalgınlıklar ve hatalara yönelik davranışsal örnekler "hata" başlığı altında ve pozitif sürücü davranışlarına yönelik rapor edilen örnekler de ve "pozitif sürücü davranışları" başlığı altında toplanmıştır. Tablo 2'de en sık rapor edilen davranış örnekleri ve parantez içinde frekansları gösterilmiştir.

\section{TQD}


Tablo 2'de de görüldüğü gibi sıklığına göre en çok yapılan ihlal davranışına örnekler; hız yapmak, kırmızı 1şıkta geçmek, şerit ihlali yapmak, hatalı sollama yapmak, günlük araç kullanma süresi ihlali yapmak, öndeki araçla aranda takip mesafesi birakmamak, uygun olmayan yerlerde yolcu indirmek/bindirmek, uygun olmayan yerlerde bekleme yapmak gibi sıradan ihlaller ve kızdığında öfkeyi ifade etmek, öteki sürücüyü rahatsız etmek amacıyla kornaya basmak, selektör yapmak, araçla sıkıştırmak gibi agresif ihlaller olarak ortaya çıkmıştır. Sıklığına göre, en çok yapılan hata davranışına örnekler; ani hareketler yapmak, aynalardan yolu kontrol etmeden hareket etmek, sinyal vermemek ve kör noktalarda kalan yol kullanıcılarını görememek olarak saptanmıştır. Sıklığına göre en çok yapılan pozitif sürücü davranışlarına örnekler; diğer yol kullanıcılarına yol vermek, ticari araç olarak trafik akışını kontrol etmek ve desteklemek, zor durumdaki araç sürücüsüne yardım etmek, gelen sürücüyü kazaya karışmaması için uyarmak, olarak ortaya çıkmıştır.

Bu sorulara ek olarak profesyonel sürücülere "iş amaçlı araç kullanmak ile şahsi araç kullanmak arasındaki farklılıklar" da sorulmuştur. Gelen cevaplar profesyonel amaçla araç kullanmanın şahsi amaçla araç kullanmaktan davranışsal bağlamda aşağıdaki noktalarda farklılaştığını ortaya koymaktadır;

Araçta kendin dışında başkalarının can ve mal güvenliğinden de sorumlu olunması, amme hizmeti (19), Özerkliğin az olması (19); hız yapma kararının daha çok çalışma şartlart ile ilgili olması örneğin; müşterinin acelesine göre, durakta ön sıraya girmek için gibi, çalışma/sürüşs saatlerinin bağll olduğun kurumca belirlenmesi, belirli bir güzergahtan gitme mecburiyeti, belirli bir zaman çizelgesine uyum sağlamak zorunluluğu olması; Çalışma/sürü̈s saatlerinin fazla olmasıyla gelen yorgunluk, dikkatsizlik ve sabırsızlığın artması (11), Tanınırlık (5); kullanılan araçla bağll olunan kurumun temsil ediliyor olmasi sebebiyle daha özenli davranışlar sergilenmesi, plakadan çalışılan kuruma ulaşılabilecek olması sebebiyle sürücü üzerindeki sorumluluğun artması

Burada ön plana çıkan ana tema profesyonel sürücülük işinin doğasına vurgu yapmakta; profesyonel sürücülerin belirli kural ve uygulamalara hem kurum seviyesinde hem de toplum ve işveren gibi denetim mekanizmaları tarafindan maruz kalmaları vurgusu taşımaktadır.

Son olarak "profesyonel sürücülerin karıştığı kazaların genellikle neden kaynaklandığı" sorusuna verilen cevaplar sıklıklarına göre aşağıda raporlanmıştır;

Uyuklama/uykusuzluk (9); Diğer yol kullanıcılart (6), örneğin; kararsız sürücüler, büyük araçların manevra şeklinin küçük araçlar tarafından bilinmemesi; Yorgunluk (4); Dikkatsizlik (4); Hatalı sollama (3); Teknik hatalar (3), örneğin; fren/lastik patlamas1, retarderin tutmamas1 vb., araç bakımının yaptırılmaması vb.; Hava koşulları (3), örneğin; sis, buz, kar; Ani hareketler (3), örneğin; ani fren, durma, dönüş vb.; Tecrübesizlik (3); Yakın takip (2); Kırmızı uşık ihlali (2); Hız yapmak (2).

En s1k raporlanan kaza sebebi olarak uykusuzluk, yorgunluk ve dikkatsizlik ön plana çıkmaktadır. Bazı sürücüler uykusuzluğu sebeplendirirken ağır çalışma koşullarından bahsetmiştir. Örneğin; uzun saatler sürüş yapmaktan kaynaklanan fiziksel yorgunluk, reflekslerin zayıflaması ve beraberinde direksiyon başında uyuklama, gözleri açık uyuma gibi. Bazı sürücüler de aynı anda birden fazla işle uğraşmaktan kaynaklanan (örneğin; yolcularla uğraşmak, değişken yol ve hava koşullarına adapte olmak, denetim mekanizmalarının farkında olmak, kapıları açıp kapama, para alıp verme, telsizle konuşma, müşteriyle konuşma vb.) zihinsel bir yorgunluktan bahsetmişlerdir. Bu yorgunluk veya uykusuzluk hali beraberinde dikkatsizliği arttırmakta ve sürücü beyanlarına göre hatalı sürücü davranışlarını doğurmaktadır.

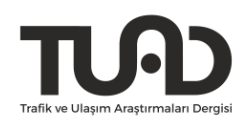


Tablo 2. Görüşmelerin içerik analizi

\begin{tabular}{|c|c|c|}
\hline İhlal & Hata & Pozitif sürücü davranışı \\
\hline Hiz yapmak (36) & $\begin{array}{l}\text { Ani hareketler yapmak (22); ani fren yapmak, ani } \\
\text { araç sollamak vb. }\end{array}$ & $\begin{array}{l}\text { Diğer yol kullanıcılarına yol vermek (24); sollama } \\
\text { sırasında, geçiș hakkı bende olsa dahi vb. }\end{array}$ \\
\hline Kırmızı ışıkta geçmek (24) & $\begin{array}{l}\text { Aynalardan yolu kontrol etmeden hareket etmek } \\
\text { (12); şerit değiştirmek, durmak kalkmak vb. }\end{array}$ & $\begin{array}{l}\text { Ticari araç olarak trafik akışını kontrol etmek ve } \\
\text { desteklemek (11); farklı durumları önceden anlayıp } \\
\text { karar vermek vb. }\end{array}$ \\
\hline Şerit ihlali yapmak (21) & $\begin{array}{l}\text { Sinyal vermeyi unutmak (10); sağa, sola dönüşlerde, } \\
\text { çıkışlarda vb. }\end{array}$ & $\begin{array}{l}\text { Zor durumdaki araç sürücüsüne yardım etmek } \\
\text { (8); kriko vermek, yol tarif etmek, sisli havalarda } \\
\text { peșime takıp yönlendirmek vb. }\end{array}$ \\
\hline Hatalı sollama yapmak (16) & $\begin{array}{l}\text { Kör noktalarda kalan yol kullanıcılarını } \\
\text { görememek (9) }\end{array}$ & $\begin{array}{l}\text { Gelen sürücüyü kazaya karışmaması için uyarmak } \\
\text { (8); dörtlüleri yakarak, kornaya basarak vb. }\end{array}$ \\
\hline Günlük araç kullanma süresi ihlali yapmak (9) & $\begin{array}{l}\text { (Bilmediğin yollarda) tabelaları kaçırıp yanlış yola } \\
\text { sapmak (6) }\end{array}$ & $\begin{array}{l}\text { Diğer araç kullanıcısına teşekkür etmek (7); } \\
\text { dörtlüleri yakarak, kornaya basarak vb. }\end{array}$ \\
\hline $\begin{array}{l}\text { Öndeki araçla aranda yeterli takip mesafesi } \\
\text { bırakmamak, takip mesafesini korumamak (9) }\end{array}$ & Aracın kontrolünü kaybetmek (6) & $\begin{array}{l}\text { Sakin kalmak, sakinliği korumak, kendini (boşver } \\
\text { gitsin diyerek) telkin etmek (7) }\end{array}$ \\
\hline Uygun olmayan yerlerde yolcu indirmek/bindirmek (8) & & Gelen araç varsa kısa farları yakmak (6) \\
\hline Uygun olmayan yerlerde bekleme yapmak (7) & & $\begin{array}{l}\text { Hatalı olduğum durumlarda özür dilemek (3); } \\
\text { elimi kaldırarak, selektörle vb. }\end{array}$ \\
\hline \multicolumn{3}{|l|}{ Ayakta yolcu almak (4) } \\
\hline \multicolumn{3}{|l|}{ Yük tonajına uymamak (4) } \\
\hline \multicolumn{3}{|l|}{ Dönüş yasağı olan yerlerden dönüş yapmak (3) } \\
\hline \multicolumn{3}{|l|}{ Sarı ışıkta geçmek (3) } \\
\hline $\begin{array}{l}\text { Kızdı̆̆ında öfkeyi ifade etmek, öteki sürücüyü rahatsız } \\
\text { etmek amacıyla; kornaya basmak (21), selektör yapmak }\end{array}$ & & \\
\hline
\end{tabular}

(16), araçla sıkıștırmak (12), araçtan inip münakaşa/kavga etmek (8), diğer aracın önüne kırmak/üstüne sürmek (7), küfretmek/sövmek (7), (camdan) el-kol işareti/hareketleri yapmak (6)), ağız dalaşına girmek, bağırmak, sözlü münakaşa (5), aracın önüne geçip ani fren yapmak (4), kendi kendine söylenmek (4), takip etmek, yakalamaya çalışmak (3)

Makas atmak (6)

Ani hareketler yapmak (22); ani fren yapmak, ani raç sollamak vb.

Aynalardan yolu kontrol etmeden hareket etme$$
\text { (8) }
$$
peşime takıp yönlendirmek vb.

, dortuleri yakarak, kornaya basarak vb. gitsin diyerek) telkin etmek (7)

(3); elimi kaldırarak, selektörle vb. 


\section{Tartışma}

\subsection{Görüşme Sonuçlarının Değerlendirilmesi}

$\mathrm{Bu}$ çalışma kapsamında farklı profesyonel sürücü gruplarından 26 sürücüyle yarı yapılandırılmış görüşmeler yapılmıştır. Sürücülerin trafikte sergiledikleri davranış örnekleri Reason'un insan hatası sinıflandırması (1990) temelinde ihlaller, hatalar ve pozitif sürücü davranışları olarak sınıflandırılmıştır. $\mathrm{Bu}$ çalışma ile profesyonel sürücülerin sürücü davranışlarının detaylı bir analizine ulaşılmıştır ve konuyla ilgili yürütülecek ileriki çalışmalara, olası iyileştirme ve müdahale programlarına zemin hazırlanmıştır. Ek olarak profesyonel sürücülerin şahsi araç kullanıcılarından farkı konusunda ve trafik kazalarına karışma sebepleri ile ilgili olarak da bilgi edinilmiştir.

Çalışmanın bulgularına göre ortak davranış örneklerinin yanı sıra işlerinin doğası gereği ve bağlı çalıştıkları kurum veya şahısla olan etkileşimleri sonucu profesyonel sürücülüğün profesyonel olmayan sürücülükten ayrıștığı görülmektedir. "Hız yapmak", "Sinyal vermeyi unutmak", "Diğer yol kullanıcılarına yol vermek" gibi maddeler ortak davranış örnekleridir. "Günlük araç kullanma süresi ihlali yapmak", "Uygun olmayan yerlerde yolcu indirmek/bindirmek", "Ayakta yolcu almak", "Yük tonajına uymamak" gibi maddeler profesyonel sürücü grupları özelinde ortaya çıkan davranış örnekleridir.

Profesyonel sürücülerin profesyonel olmayan sürücülerden farklılaşan davranış örnekleri daha detaylı incelendiğinde farklılığın çoğunlukla profesyonel sürücülerinin mesleklerinin doğası gereği ortaya çıkan bir durum olduğu görülmektedir. Raporlanan ihlal davranışı örneklerine bakıldığında profesyonel olan ve olmayan sürücüler arasında trafik kurallarını ihlal etmeleri konusunda bazı benzer motivasyonlar olsa da (örn; aciliyet gibi), bazı farklılıklar da ortaya çıkmıştır. Örneğin; profesyonel sürücüler yapmış olduğu bazı ihlalleri, kendi kontrolleri dışında 3. şahısların (örn; yolcu, kurum vb.) talepleri ile ilişkilendirmişlerdir; "yükü hedef lokasyona zamanında yetiştirmek için bazı ihlaller yapmak", "müşterinin acelesine göre hız yapma" gibi. En çok raporlanan ihlal davranışının "hız yapmak" olarak ortaya çıkması da literatüre paralel bir bulgudur (Sullman ve ark., 2002; Reason ve ark., 1990). Bunun yanı sıra, sürücünün aracının büyüklüğü (kamyon ya da taksi olması gibi), kimi ya da neyi taşıdığı (yolcu ya da mal taşıması gibi), işin ek talepleri olup olmaması (müşteriyle iletişim, para alışverişi, araç kapılarını açıp kapama gibi), raporlanan hatalı davranış örneklerini sebeplendirme konusunda kendini göstermiştir. Useche, Ortiz ve Cendales'in 2017 yılında yaptıkları çalışmada da değindikleri gibi, bir işin talepkarlığı arttıkça, yapılan hata ve ihlaller artmaktadır. Pozitif sürücü davranışları yakından incelendiğinde trafikte işleri gereği daha fazla vakit geçiren profesyonel sürücülerin güvenli trafik ortamını önemsedikleri, trafik akışını kontrol edip yönlendirdikleri, farklı durumları öngörüp uygun olarak harekete geçtikleri, zor durumdaki yol kullanıcılarına yardım ettikleri (sisli havada şahsi araç sürücülerini yönlendirmek gibi) ve hatta gelen sürücüyü kazaya karışmaması için uyardıkları beyanlarından anlaşılmaktadır. Özkan ve Lajunen'in de çalışmalarında belirttiği gibi (2005), trafikteki güvenli işleyişinin devam etmesine yönelik sergilenen pozitif sürücü davranışları profesyonel sürücü grubu tarafından da çeşitli örneklemelerle birlikte rapor edilmiştir.

Daha az özerkliğe sahip olan profesyonel sürücülerin; işlerinin getirdiği bazı sorumluluk ve zorunluluklar açısından daha esnek sürüş koşullarına sahip şahsi araç sürücülerinden ayrıştığı görülmektedir. Örneğin; taşınan yolcu veya malın sürücüye ek bir sorumluluk yüklemesi, bağlı çalışılan kurum veya şahsa yönelik duyulan sorumluluk hissi, güzergah seçiminde önceden belirlenen rotaların takip edilmesi zorunluluğu gibi hususlar profesyonel sürücülüğün profesyonel olmayan sürücülükten ayrılan noktalarına işaret etmektedir. Bunlara ek olarak çalışma ve mola saatlerinin kurumca belirlenmesi ve hatta bazı durumlarda aşırı iş yüklemesi

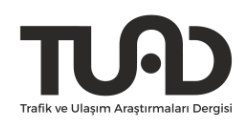


yapılması (örneğin; uzayan çalışma saatleri, işin teslimi için acele edilmesi) da bulgular arasındadır. Bu bulguyla ilişkili olarak literatürde, çalışma saatleri konusunda net olan kurumlarda sürücülerin daha az hata ve ihlal rapor ettiği arasındaki ilişki vurgulanmıştır (Öz ve ark., 2014). Ek olarak Sullman ve ark. 2002 y1lında kamyon sürücüleriyle yaptıkları çalışmalarında da dikkat çektikleri gibi profesyonel sürücülerin araç tipleri dolayısıyla toplum tarafından tanınırlığı olması ve yaptıkları davranışların takibinin kolaylıkla yapılabileceği de şahsi araç sürücülerinden ayrışan diğer bir unsur olarak ortaya çıkmıştır.

Profesyonel sürücülerin beyan ettikleri kazaya karışma nedenleri incelendiğinde ise uykusuzluk, yorgunluk ve beraberinde gelen dikkatsizlik ön plana çıkmaktadır. Sürücüler bu unsurların ağır çalışma şartları ile ilintili olduğunu beyanlarında vurgulamıştır. Hem fiziksel hem de bilişsel yorgunluk sebebiyle sürüş sırasında uyuklama sonucu kazalara karıştıklarını beyan etmişlerdir. Bu bulguyla ilintili olarak Bunn, Slavova, Struttmann ve Browning (2005) profesyonel sürücülerin profesyonel olmayan sürücülere kıyasla uykusuzluktan kaynaklanan kazalara daha fazla karıştıklarını rapor etmişlerdir. Dawson ve Reid (1997) kazaların ve ciddi yaralanmaların $29 \%$ ile $50 \%$ aralığında değişen bir oranla uykusuzluktan kaynaklandığ çalışmalarında ifade etmişlerdir.

Bunlara ek olarak profesyonel sürücüler kendi içlerinde de sürdükleri araç tipine göre farklı davranışlar sergileyebilmektedir. Örneğin; sürdükleri araç tipine bağlı olarak profesyonel sürücülerin uymaları gereken bazı ekstra kurallar (sürüş ve mola zamanları, yük taşıma limitleri vb.) olabilmektedir. Bu farklılık da beyan edilen davranışlarda ve beyan edilme sıklıklarında kendini göstermektedir. Örneğin; "Ayakta yolcu almak" maddesi dolmuş ve otobüs sürücüleri için geçerli olabilecek bir sapkın sürücü davranışı iken taksi sürücüleri için böyle bir madde anlamlı değildir. "Kör noktada kalan yol kullanıcılarını görememek" maddesi büyük araçlar için anlamlı olabilirken daha küçük boyutta araçlar için anlamlı olmayabilir. Bu konu ile ilgili olarak şimdiki çalışmada farklı sürücü grupları az sayıda katılımcı ile temsil edildiğinden sürücü grubu özelinde ayrışan davranış örnekleri vurgulanmamıştır. Profesyonel sürücü davranışları; sürdükleri aracın büyüklüğü, çalışma saatleri, bir kuruma bağlı çalışıp çalışmadıkları, kimi ya da neyi taşıdıkları gibi işlerinin doğasından kaynaklanan farklılıklar bakımından profesyonel olmayan sürücülerin sürücü davranışlarından ayrışmaktadır. İleriki çalışmaların çeşitli profesyonel sürücü gruplarından daha fazla sürücü ile görüşme yapmaları ve sürücü grubu özelinde ayrışan davranış örneklerini de analiz etmeleri tavsiye edilmektedir. $\mathrm{Bu}$ sayede her bir farklı profesyonel sürücü grubu özelinde de sürücü davranışlarının derinlemesine anlaşılmasına katkı sağlanabilir.

Çalışma bulgularından hareketle, güvenli davranışların arttırılması, riskli davranışların ve beraberinde gelebilecek olası kazaların azaltılması hedefiyle bir takım iyileştirme ve müdahale önerilerinde bulunulmuştur. Örneğin; profesyonel sürücüler için kişiler ve kurumlar bazında denetimlerin arttırılması, hatalı davranışlara ceza verilmesi, kurumların kendi güvenlik iklimlerini geliştirmeye yönelik çalışmalarda bulunması ve bunun bir parçası olarak sürücülerine periyodik olarak güvenli sürüş üzerine eğitimler vermesi, kurumlarca güvenli davranışların ödüllendirilmesi bu önerilerden bazılarıdır. Özellikle kazaya karışma konusunda ön plana çıkan uykusuzluk, yorgunluk faktörlerine yönelik çalışma koşullarında düzenlemelere gidilmesi ve bu yorgunlukla baş etme veya yorgunluğu yönetme konusunda sürücülere uygulayabilecekleri stratejiler konusunda bilgi verilmesi riskli sürücü davranışlarının azalmasına ve güvenli sürüşün teşvik edilmesine katkıda bulunabilir.

$\mathrm{Bu}$ çalışmanın bazı kısıtlılıkları bulunmaktadır. Görüşmelere katılan katılımcıların hepsi erkektir. Türkiye'de bu meslek grubu ağırlıklı olarak erkeklerden oluşmaktadır. İleriki çalışmalar profesyonel kadın sürücüleri de çalışmalarına dahil edebilir ve profesyonel sürücülerin trafikte sergiledikleri sürücü davranışlarını cinsiyet bağlamında kıyaslayabilirler.

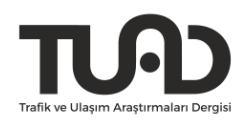


Ek olarak, bu çalışmada öz beyana dayalı bir ölçüm yöntemi kullanılmıştır. Bu çalışmadaki yöntem, gözlem yöntemiyle birleştirilip çalışma zenginleştirilebilir.

Bu çalışma profesyonel sürücü davranışlarını derinlemesine inceleyen nitel bir çalışma olması yönüyle güçlüdür. Çeşitli profesyonel sürücü gruplarının çalışmaya dahil edilmesi ile zengin bir içerik elde edilmiş, güvenlikle ilgili olabilecek davranış örnekleri teorik temelde ayrıştırılmıştır. Bu çalışmadan; hem uygulamada profesyonel sürücü grubuna yönelik yapılacak iyileştirme ve müdahale çalışmalarında, hem de teorik olarak var olan ölçüm araçlarının güncellenmesi ve yeni araçların geliştirilmesine katkı sağlamak için faydalanılabilir. 


\section{Kaynakça}

af Wåhlberg, A., Dorn, L. ve Kline, T. (2011). The Manchester Driver Behaviour Questionnaire as a predictor of road traffic accidents. Theoretical Issues in Ergonomics Science, 12(1), 66-86.

Baker, S. P., Wong, J. W. ve Baron, R. D. (1976). Professional drivers: Protection needed for a high-risk occupation. American Journal of Public Health, 66(7), 649-654.

Baughan, C., Pearce, L., Smith, L. ve Buckle, G. (2003). Work-related road accidents. TRL Report 582. Crowthorne: Transport Research Laboratory.

Bunn, T. L., Slavova, S., Struttmann, T. W. ve Browning, S. R. (2005). Sleepiness/fatigue and distraction/inattention as factors for fatal versus nonfatal commercial motor vehicle driver injuries. Accident Analysis and Prevention, 37(5), 862-869.

Caird, K. J. ve Kline, T. J. (2004). The relationships between organizational and individual variables to on-the-job driver accidents and accident-free kilometers. Ergonomics, 47 (15), 1598-1613.

Dawson, D. ve Reid, K. (1997). Fatigue, alcohol and performance impairment. Nature, 388(6639), 235.

Dula, C. S. ve Ballard, M. E. (2003). Development and evaluation of a measure of dangerous, aggressive, negative emotional, and risky driving. Journal of Applied Social Psychology, 33(2), 263-282.

Elander, J., West, R. ve French, D. (1993). Behavioural correlates of individual differences in road traffic crash risk: An examination of methods and findings. Psychological Bulletin, 113, 279-294. doi:10.1037/0033-2909.113.2.279.

Freeman, E., Davey, D. ve Wishart, E. (2008). A study of contemporary modifications to the Manchester Drivers Behaviour Questionnaire for organizational fleet settings. In Dorn, Lisa (Ed.) Driver Behaviour and Training, Vol 3. Human Factors in Road and Rail Safety. Aldershot, Ashgate, 201-214.

Harris, P. B., Houston, J. M., Vazquez, J. A., Smither, J. A., Harms, A., Dahlke, J. A. ve Sachau, D. A. (2014). The prosocial and aggressive driving inventory (PADI): A self-report measure of safe and unsafe driver behaviors. Accident Analysis and Prevention, 72, 18. doi:10.1016/j.aap.2014.05.023.

Lam, L. T. (2004). Environmental factors associated with crash-related mortality and injury among taxi drivers in New South Wales, Australia. Accident Analysis and Prevention, 36(5), 905-908.

Lawton, R., Parker, D., Manstead, A. S. R. ve Stradling, S. G. (1997). The role of affect in predicting social behaviours: The case of road traffic violations. Journal of Applied Psychology, 27, 1258-1276. doi:10.1111/j.1559-1816. 1997.tb01805.x.

Newnam, S., Greenslade, J., Newton, C. ve Watson, B. (2011). Safety in occupational driving: Development of a driver behavior scale for the workplace context. Applied Psychology, 60(4), 576-599. 
Newnam, S., Watson, B. ve Murray, W. (2002). A comparison of the factors influencing the safety of work-related drivers in work and personal vehicles. Proceedings of the 2002 Road Safety Research, Policing and Education Conference, 4-5 November, Adelaide, Australia, 488-494.

Newnam, S., Watson, B. ve Murray, W. (2004). Factors predicting intentions to speed in a work and personal vehicle. Transportation Research Part F: Traffic Psychology and Behaviour, 7(4-5), 287-300.

Oppenheim, I. ve Shinar, D. (2011). Human factors and ergonomics. In Handbook of Traffic Psychology (s. 193-211). doi:10.1016/B978-0-12-381984-0.10015-3.

Öz, B., Özkan, T. ve Lajunen, T. (2013). An investigation of professional drivers: Organizational safety climate, driver behaviours and performance. Transportation Research Part F: Traffic Psychology and Behaviour, 16, 81-91.

Öz, B., Özkan, T. ve Lajunen, T. (2014). Trip-focused organizational safety climate: Investigating the relationships with errors, violations and positive driver behaviours in professional driving. Transportation Research Part F: Traffic Psychology and Behaviour, 26, 361-369.

Özkan, T. ve Lajunen, T. (2005). A new addition to DBQ: Positive driver behaviours scale. Transportation Research Part F, 8, 355-368. doi: 10.1016/j.trf.2005.04.018.

Rasmussen, J. (1983). Skills, rules, and knowledge; signals, signs, and symbols, and other distinctions in human performance models. IEEE Transactions on Systems, Man, and Cybernetics, (3), 257-266.

Reason, J. T. (1990). Human error. Cambridge University Press: New York.

Reason, J. T., Manstead, A., Straddling, S. G., Baxter, J. ve Campbell, K. (1990). Errors and violations on the road - A real distinction. Ergonomics, 33(10/11), 1315-1332.

Sullman, M. J., Meadows, M. L. ve Pajo, K. B. (2002). Aberrant driving behaviours amongst New Zealand truck drivers. Transportation Research Part F: Traffic Psychology and Behaviour, 5(3), 217-232.

Tanvir, S., Habib, N. Z. ve Walker, G. H. (2018, July). A Qualitative Investigation of Professional Driver Behavior Due to Socio-Economic, Cultural, Religious Factors and Its Impact on Dubai Road Safety. In International Conference on Applied Human Factors and Ergonomics (s. 764-775). Springer, Cham.

Taubman-Ben-Ari, O., Mikulincer, M. ve Gillath, O. (2004). The multidimensional driving style inventory-scale construct and validation. Accident Analysis and Prevention, 36(3), 323-332.

Türkiye İstatistik Kurumu (2017). Karayolu Trafik Kaza İstatistikleri, 2016. Retrieved from http://www.tuik.gov.tr/PreHaberBultenleri.do?id=24606

Useche, S. A., Ortiz, V. G. ve Cendales, B. E. (2017). Stress-related psychosocial factors at work, fatigue, and risky driving behavior in bus rapid transport (BRT) drivers. Accident Analysis and Prevention, 104, 106-114.

Wang, Y., Li, L., Feng, L. ve Peng, H. (2014). Professional drivers' views on risky driver behaviors and accident liability: A questionnaire survey in Xining, China. Transportation Letters, 6(3), 126-135. 
Wills, A. R., Watson, B. ve Biggs, H. C. (2006). Comparing safety climate factors as predictors of work-related driver behavior. Journal of Safety Research, 37(4), 375-383.

World Health Organization (2018). Global Status Report on Road Safety 2018. Retrieved from www.who.int/violence_injury_prevention/road_safety_status/2018/en/. 